\title{
O ENSINO DE TEATRO NOS CURSOS TÉCNICOS INTEGRADOS DO IFRN
}

\author{
M. N. MOURA \\ ${ }^{1}$ Instituto Federal de Educação, Ciência e Tecnologia do Rio Grande do Norte \\ marinalva.moura@ifrn.edu.br
}

Artigo submetido em novembro/2011 e aceito em dezembro/2011

\section{RESUMO}

Nesse trabalho, apresentamos uma reflexão sobre a sensibilidade estética expressa no corpo e nos gestos da narração de história em sala de aula, com intuito de ensinar teatro. O desenvolvimento dessa reflexão se dá a partir da atitude fenomenológica inspirada no filósofo francês Maurice Merleau-Ponty, na qual o corpo deixa de ser só um instrumento para significar no acontecimento teatral, realizando uma comunicação sensível na reflexibilidade corpórea. Os gestos do narrador nos dão a ver e a pensar sobre a linguagem e a comunicação do corpo, oferecendo-nos processos sensíveis e modos criativos de aprendizagem. Nessa perspectiva, a reflexão sobre o fenômeno do acontecimento teatral realizado em sala de aula, apresenta a narrativa de história como processo educativo do corpo, configurando-se como uma aprendizagem do fazer teatral. Um conhecimento sensível que pode contribuir com as reflexões sobre teatro e educação.

PALAVRAS-CHAVE: corpo, gesto, narração de história, educação e teatro.

\section{THEATRE TEACHING IN TECHNICAL STUDIES OF INTEGRATED IFRN}

\section{ABSTRACT}

In this paper, we present a reflection on the aesthetic sensibility expressed in the body and gestures of storytelling in the classroom, aiming to teach theater. The development of this reflection occurs from the phenomenological attitude inspired by the French philosopher Maurice Merleau-Ponty, in which the body is no longer just an instrument to mean the theatrical event, performing a sensitive communication in the body reflectance. The gestures of the narrator gives us to see and think about the body language and communication, providing us with sensitive processes and creative ways of learning. From this perspective, reflection on the phenomenon of theatrical event held in the classroom, presents the narrative of history as an educational process of the body, configured as a learning to do theater. A sensitive knowledge that can contribute to the reflections on theater and education.

KEY-WORDS: body, gesture, storytelling, education and theater. 


\section{O ENSINO DE TEATRO NOS CURSOS TÉCNICOS INTEGRADOS DO IFRN}

\section{INTRODUÇÃO}

Entendemos que a fenomenologia é uma forma de reaprender a ver o mundo, e oferece-nos possibilidades de conhecimentos, nas quais pensar não é possuir objetos de pensamento, mas sim refletir sobre o irrefletido. Pensar é sempre relação do ser no mundo, que por sua vez é sempre aprendizagem. O ser do qual falamos não sobrevoa o corpo, mas é o próprio corpo, que na relação com o mundo cria uma linguagem sensível.

Para nós educar é criar e recriar sua história, sua cultura. Educação na perspectiva da fenomenologia considera o homem em sua complexidade, é uma educação dos sentidos, na qual o corpo funda a experiência perceptiva. Educação é também relação do ser no mundo, fonte para o conhecimento, pois conhecer é atribuir sentidos aos acontecimentos.

De fato é grande o número de pesquisadores que dedicaram seus trabalhos de pesquisa falando sobre o corpo no teatro e na educação. Nóbrega (2010) questiona-se se há ainda algo a ser dito e responde: "Talvez não, mas a impressão é de que falta muito a ser realizado quando se trata de considerar o corpo nas práticas educativas para além de sua instrumentalização em processos de aprendizagem" (NÓBREGA, 2010, p. 114).

Precisamos ir mais longe, assim como dizia Van Ghogh quando pintava os Corvos. Para Merleau-Ponty (2004) "ir mais longe" de Van Ghogh "já não indica alguma realidade para a qual seria preciso caminhar, mas o que falta fazer para restituir o encontro do olhar com as coisas que o solicitam, daquele que tem de ser com aquilo que é." (MERLEAU-PONTY, 2004, p. 88). O que buscamos é a restituição da sensibilidade estética como conhecimento do corpo na aprendizagem do fenômeno do acontecimento teatral em sala de aula.

Aproximamo-nos da fenomenologia para ensinar o sentir mesmo do acontecimento teatral em sala de aula, observando-o e considerando com as adversidades encontradas. Para tanto, o teatro aqui não é uma representação do corpo, realizada por um sujeito que o sobrevoa, mas sim uma experiência do acontecimento, é uma linguagem sensível na qual a expressão é comunicação.

Acreditar que a experiência estética é resignificar o espaço da sala de aula, para tanto recorremos à narrativa de história, no intuito de que ela eduque e possa vir a transformar-se num logos estético. Desta forma, nos perguntamos: Como o conhecimento sensível da narrativa de histórias pode contribuir com o ensino de teatro?

A arte de narrar é uma experiência do corpo, na qual quem narra retira da sua própria experiência o que conta, incorporando a história que conta a experiência dos seus ouvintes. Assim, narrar é uma experiência que passa de pessoa para pessoa, ocorrendo um entrelaçamento nas tramas da história. Narrar é um trabalho de artesão, de fiador que é passado de geração para geração.

Benjamin (1994) nos diz que narrar histórias é uma forma artesanal de comunicação. E a narrativa é a arte de contar de novo uma história, caso as histórias não sejam mais contadas, ficariam perdidas, como um fio que se perde do tecido que fiado. $O$ conhecimento é o fio que é tecido enquanto se ouve a história.

A narrativa, que durante tanto tempo floresceu num meio artesão - no campo, no mar e na cidade -, é ela própria, num certo sentido, um forma artesanal de comunicação. Ela não está interessada em transmitir o "puro em si" da coisa narrada 
como uma informação ou um relatório. Ela mergulha a coisa na vida do narrador para em seguida retirá-la dele (BENJAMIN, 1994, p. 205).

Flávio Desgranges, inspirado na pesquisa de Philippe Meirieu ${ }^{1}$, refere-se ao valor educacional da arte dramática nos seguintes termos: "Na tentativa de compreender a atitude proposta ao espectador teatral enquanto experiência educacional, podemos recorrer ao enfoque sutil presente na alegoria benjaminiana (Benjamin, 1994), que sugere que o ouvinte de uma história - ao ouvi-la, compreendê-la em seus detalhes e empreender uma atitude interpretativa - choca os ovos da própria experiência, fazendo nascer deles o pensamento crítico" (DESGRANGES, 2006, p. 24).

O teatro é uma narrativa simbólica que se vale de vários elementos para significar: os gestos, as sonoridades, os figurinos, os objetos cênicos, a dramaturgia, etc. Cada um destes elementos de linguagem colabora para a narrativa da história, e cabe ao espectador criar suas significações e interpretar o conjunto dos símbolos que se apresentam, e que se renovam a cada instante.

Esta experiência do jogo teatral é provocadora e convida o espectador conhecer os elementos dessa linguagem. Nesse sentido, a experiência teatral desafia o espectador a, deparando-se com a linguagem própria desta arte, criar significações e interpretar os diversos símbolos presentes em uma encenação.

Nesse modo de ensinar, criando e recriando, descobrimos que o importante não é o ensino a partir da aplicação de modelos técnicos de jogo teatral, mas sim que o importante é ensinar a magia do acontecimento teatral, a sensação do fenômeno e o que constitui o suficiente para que o mesmo ocorra. Comecemos como uma história.

A história que contamos a seguir é à experiência vivida como professora de Arte do IFRN, na qual trabalho com as disciplinas: Arte nos cursos profissionalizantes no nível técnico integrado, e Arte e Educação nos curso de graduação em licenciatura de Física, Geografia e Espanhol. Nos cursos de graduação não trabalhamos com a criação de espetáculo, trabalhamos com o diálogo entre um espetáculo e essas áreas de conhecimento, finalizando com um texto científico e um plano de aula que trabalhe a interdisciplinaridade.

A disciplina de Arte na Instituição é ensinada a partir da referência das Orientações Curriculares do Ensino Técnico Integrado, devolvida nas seguintes linguagens: teatro, dança, artes visuais e música. $O$ ensino de arte ocorre no período de três semestres, de modo que, a cada semestre, o aluno tenha contato com diferentes linguagens da arte: artes visuais, artes cênicas e música. De modo que ao longo do curso o aluno tem contato com as diferentes linguagens e com professores com formação especifica em cada uma das linguagens.

\section{ERA UMA VEZ...}

Era uma vez uma sala de aula com cadeiras, carteiras, quadro branco, projetor de imagem, computador e televisão, num canto da sala também tem uma lixeira, onde nem sempre se guarda o lixo, o lixo muitas vezes era jogado no chão da sala.

\footnotetext{
${ }^{1} \mathrm{O}$ educador francês Philippe Meirieu, interessado em investigar mais profundamente a questão da arte e educação, realizou em 1992 uma pesquisa com crianças de 6 a 12 anos, habitantes da periferia da cidade de Lyon. Meirieu, analisando as entrevistas com essas crianças ressalta que "aquelas habituadas a freqüentar salas de teatro, de cinema e a ouvir histórias demonstram maior facilidade de conceber um discurso narrativo, de criar histórias e de organizar e apresentar os acontecimentos da própria vida" (MEIRIEU in DESGRANGES, 2006, p 2223).
} 
Uma professora de teatro entra em sala para narrar histórias. As salas foram diversas, mas a professora era sempre a mesma, os ex-alunos foram aumentando, passaram de séries, mas todos sentaram e ouviram histórias.

As histórias contadas pela professora não são recentes, são de tempos passados, vem de muito longe e foram se modificadas de acordo com seus contadores. Essas histórias falam do teatro de hoje, mas também do que a história nos ensina sobre o tempo em que a expressão dramática começou a aparecer nas expressões do homem feitas nas paredes de cavernas.

Foram os professores da professora que the contaram algumas dessas histórias, outras ela aprendeu no teatro, outras ela aprendeu nos livros e trouxe para contar à seus alunos em sala de aula. Do mesmo modo que seus professores, a professora pede a seus alunos para serem narradores dessa histórias que ouviram, e que vão atrás de outras nos livros, nos teatros e na escuta cotidiana. A professora entende que assim passarão também a ser narradores de histórias, desejando que elas sobrevivam na memória de quem as contou e escutou.

A experiência com a narrativa de histórias vai sendo guardada em caixinhas e solicitadas quando o desejo do corpo se faz presente e começa-se a contar uma história. Essa história que vai ser contada é fiada com o fio da experiência vivida pelo narrador. A história começa a ser fiada, os fios escolhidos vão montando os personagens, o espaço, as ações e os rumos que a história deva seguir. Os fios da experiência vivida aumentam o desejo de ouvir e narrar novas histórias. E assim, passamos a criação do teatro na escola.

A sala de aula agora é ampla sem carteiras e com muitas cadeiras, é um auditório. Tem um palco com entrada e saídas de cena e seus corredores são grandes. O som ocupa todo o ambiente e a luz é comanda por vários interruptores, naquele espaço os alunos podem usar roupas de personagem e não suas fardas da escola.

No momento em que os alunos passam as ser narradores, a professora ensina-os que conhecer a história contada é mais importante que decorar a história; realizar ações em cena como personagem é mais importante que fazer marcas de movimentação no palco; compreender a criação do figurino, do cenário e da iluminação é mais importante do que não ter o material mais atual para confeccioná-lo; e por fim, criar novas dramaturgias inspiradas nas histórias antigas é mais importante do que repetir a história tal qual alguém escreveu.

A turma agora está dividida em grupos e o horário de aula da professora também, ela trabalha com os grupos separados e no início não permite que um grupo participe do horário do outro grupo. Começam os ensaios, alguns são realizados com a professora na sala de aula, outros não, são realizados pelos alunos em lugares escolhidos por eles. A professora chama a atenção para a realização dos ensaios extraclasse, e lhes dá tarefas a serem realizadas nos ensaios com ela em sala de aula. A professora começa a ver pelos corredores da escola grupos de alunos se preparando, alguns conversam com ela e tiram suas dúvidas, outros dizem que vão ensaiar. Os ensaios são muitos, mas dura pouco tempo, tem menos de um mês para o dia em que os alunos serão os narradores das histórias...

Durante os ensaios a professora pede aos alunos que não se esqueçam do espectador, aliás, é para ele que a história é contada, e como o palco é distante das cadeiras pede para que os alunos falem alto e não fiquem de costas, pois escondem a cena e o espectador não acompanha a história.

O dia da apresentação está próximo e a professora marca o ensaio geral, convida os outros grupos da turma para assistir e avisa-os que eles são espectadores diferentes, ao final da apresentação eles avaliaram o espetáculo apontando o que está bom e o que precisa melhorar para o entendimento da história. É também o período de convidar os espectadores para o acontecimento do espetáculo e a 
professora pede aos alunos que distribua cartazes pela escola avisando do acontecimento, cada grupo deverá divulgar o seu espetáculo.

Antes da apresentação temos um ensaio com iluminação cênica, como a escola não dispõe desse material ele é alugado e só é possível ensaiar com ele um dia antes da apresentação do espetáculo. Nesse ensaio, o aluno responsável pela iluminação precisa aprender a realizá-la com esse material, a professora reconhece que essa não é uma situação ideal, mas sabe também que a magia criada e as possibilidades plásticas da luz são muitas e incentiva os alunos a usá-las. Lembra-o também de que o importante não é o material, mas a história contada pela luz. Pela narrativa de histórias chegamos ao acontecimento teatral, esse fundo imemorial do corpo que pode ser encontrado onde quer que as pessoas se reúnam na esperança de que a magia da percepção os transportem para outra realidade possível. Esse é o teatro de toda gente, não só o teatro dos livros, das salas de espetáculo, mas o teatro mesmo, que pode acontecer em qualquer lugar e em qualquer momento, basta que ali seja invocada a necessidade do corpo de narrar suas histórias.

Para finalizar gostaríamos de destacar o pensamento de Cação Fontana (2001).

\begin{abstract}
Diferentemente de todos os outros professores com quem convivera até então, essa mulher lia para nós... Lia, declamava e, enquanto o fazia, seus olhos e sua voz transmutavam-se. A professora transformava-se em intérprete. 0 texto transformava-se em acontecimento[...] Lendo de viva voz, a professora instaurava na sala de aula uma relação sensível com o texto, medida por sua paixão pela palavra e pela cálida corporeidade de sua voz, provocando nossa atenção de alunos e de leitores para a dimensão sensorial que a palavra oral guarda e cujas influências foram reconhecidas por todos os que desde a Antiguidade se preocuparam com a eficácia da palavra[...] Era a lógica mesma da fala professoral que aquela mulher implodia, deixando que a literatura prevalecesse sobre a pedagogização, que a paixão pela palavra prevalecesse sobre a homogeneização dos sentidos, a emoção da experiência sobre o saber que vale por si mesmo, a corporeidade pulsante sobre a negação do corpo. Tanto assim, que dela e com ela aprendi algo que nunca enunciou: um princípio educativo de extrema corporeidade - a paixão de ensinar- sintetizado em uma expressão de poeta soviético lessênin citado por Kusnet: se você não estiver ardendo não poderá inflamar ninguém (FONTANA, 2001, p.48-50).
\end{abstract}

$\mathrm{Na}$ experiência descrita por Cação Fontana à professora instaura em sala de aula um conhecimento sensível, provocando os alunos para ouvirem histórias, de forma tal que a dimensão pedagógica passa a ser também sensorial, ocorre uma comunicação sensível realizada nos movimentos do corpo em comunhão com o mundo, essa situação nos remete ao próprio logos do mundo.

Nesse sentido a aprendizagem se dá pelos movimentos realizados pelo corpo em situação teatral. O corpo é reversível e sua a reversibilidade é sempre conhecimento, a mão que toca e é tocada, o olho que olha e é olhado... É a própria comunhão do ser no mundo, nela já não se sabe o que é um ou outro, são um entre, vivenciamos o tempo todo uma experiência do ser atado as coisas do mundo.

Desta forma, o teatro passa a ser um gesto coletivo expresso pela estesia do corpo no acontecimento teatral. A estesia do corpo de que falamos encontra-se na arte do narrador de história, uma atitude do ser no mundo, uma aprendizagem do corpo que se dá na experiência vivida. Quem conta uma história passa adiante uma experiência vivida, e ao mesmo tempo em que conta vive naquele momento uma nova experiência. 
Retornando a professora de nossa história, o que ela deseja é está ardendo para inflamar os seus alunos. A experiência como professora narradora de história, aponta para a experiência teatral com acontecimento do corpo, um conhecimento sensível, diferente do dualismo que separa o corpo do pensamento. Aqui a palavra é gesto e sua significação um mundo.

\section{REFERÊNCIAS BIBLIOGRÁFICAS}

1. NÓBREGA, Terezinha Petrucia. Uma fenomenologia de corpo. São Paulo: Editora Livraria da Física, 2010.

2. MERLEAU-PONTY, Maurice. A linguagem indireta e as vozes do silêncio. In $\mathrm{O}$ olho e o espírito. São Paulo: Cosac \& Naify, 2004.

3. BENJAMIN, Walter. O narrador - Considerações sobre a obra de Nikolai Leskov. In Mágia e técnica, arte e política. São Paulo: Brasiliense, 1994.

4. DESGRANGES, Flávio. Pedagogia do teatro: provocação e dialogismo. São Paulo: HUCITEC, 2006.

5. FONTANA. Roseli A. C. O corpo aprendiz. In: CARVALHO, Yara Maria de; RUBIO, Katia (org.). Educação física e ciências humanas. Hucitec: São Paulo, 2001. p. 41-52. 